\title{
Functional Properties of Neurons Derived from In Vitro Reprogrammed Postnatal Astroglia
}

\author{
Benedikt Berninger, ${ }^{1,2}$ Marcos R. Costa, ${ }^{2}$ Ursula Koch, ${ }^{3}$ Timm Schroeder, ${ }^{2}$ Bernd Sutor, ${ }^{1}$ Benedikt Grothe, ${ }^{3}$ and \\ Magdalena Götz ${ }^{1,2}$ \\ ${ }^{1}$ Department of Physiological Genomics, Institute of Physiology, Ludwig-Maximilians University Munich, D-80336 Munich, Germany, ${ }^{2}$ Institute for Stem \\ Cell Research, National Research Center for Environment and Health, D-85764 Neuherberg, Germany, and ${ }^{3}$ Department Biologie II, Division of \\ Neurobiology, Ludwig-Maximilians University Munich, D-82152 Planegg-Martinsried, Germany
}

With the exception of astroglia-like cells in the neurogenic niches of the telencephalic subependymal or hippocampal subgranular zone, astroglia in all other regions of the adult mouse brain do not normally generate neurons. Previous studies have shown, however, that early postnatal cortical astroglia in culture can be reprogrammed to adopt a neuronal fate after forced expression of Pax6, a transcription factor (TF) required for proper neuronal specification during embryonic corticogenesis. Here we show that also the proneural genes neurogenin-2 and Mash1 (mammalian achaete schute homolog 1) possess the ability to reprogram astroglial cells from early postnatal cerebral cortex. By means of time-lapse imaging of green fluorescent astroglia, we provide direct evidence that it is indeed cells with astroglial characteristics that give rise to neurons. Using patch-clamp recordings in culture, we show that astroglia-derived neurons acquire active conductances and are capable of firing action potentials, thus displaying hallmarks of true neurons. However, independent of the TF used for reprogramming, astroglia-derived neurons appear to mature more slowly compared with embryonic-born neurons and fail to generate a functional presynaptic output within the culturing period. However, when cocultured with embryonic cortical neurons, astroglia-derived neurons receive synaptic input, demonstrating that they are competent of establishing a functional postsynaptic compartment. Our data demonstrate that single TFs are capable of inducing a remarkable functional reprogramming of astroglia toward a truly neuronal identity.

Key words: stem cells; neurogenesis; astrocyte (astroglia); transcription factor; gene transfer; regeneration

\section{Introduction}

During development, neurogenic progenitors are progressively depleted in the mouse forebrain (Malatesta et al., 2000; Morrow et al., 2001), becoming finally restricted to the ventricular subependymal zone (SEZ) and hippocampal subgranular zone at postnatal stages and adulthood. Notably, telencephalic neurogenic progenitors display astroglial characteristics in the embryonic (Malatesta et al., 2000; Miyata et al., 2001; Noctor et al., 2001; Tamamaki et al., 2001), postnatal (Merkle et al., 2004; Ventura and Goldman, 2007), and adult (Doetsch et al., 1999; Seri et al., 2001; Garcia et al., 2004; Seri et al., 2004) brain, provoking the question whether astroglia of non-neurogenic regions retain some precursor-like properties. In support of this, glial cells in the postnatal and adult CNS can be manipulated to undergo the initial steps of neurogenesis both in vitro and, after brain injury,

\footnotetext{
Received Dec. 12, 2006; revised June 6, 2007; accepted June 7, 2007

This work was supported by grants from the Deutsche Forschungsgemeinschaft and the Bavarian State Ministry of Sciences, Research, and the Arts. We thank Dr. Leanne Godinho for critical reading of and helpful discussion on this manuscript and Dr. François Guillemot for generously providing retroviral vectors. We are also very grateful to Mücella Öçalan, Andrea Steiner-Mezzadri, and Tatiana Simon-Ebert for their excellent technical assistance.

Correspondence should be addressed to either Dr. Magdalena Götz or Dr. Benedikt Berninger, Department of Physiological Genomics, Institute of Physiology, Ludwig-Maximilians University Munich, Schillerstrasse 46, D-80336 Munich, Germany. E-mail: magdalena.goetz@gsf.de or benedikt.berninger@gsf.de.

D0I:10.1523/JNEUROSCI.1615-07.2007

Copyright $\odot 2007$ Society for Neuroscience $\quad 0270-6474 / 07 / 278654-11 \$ 15.00 / 0$
}

in vivo (Kondo and Raff, 2000; Laywell et al., 2000; Heins et al., 2002; Zheng et al., 2004; Buffo et al., 2005).

One of the factors previously identified to endow glial cells with neurogenic potential is the transcription factor (TF) Pax6 (paired box gene 6). Pax6 is expressed in radial glia of the developing cortex (Götz et al., 1998) and is indispensable for cortical neurogenesis from these cells (Warren et al., 1999; Heins et al., 2002). Moreover, Pax6 plays a crucial role in the generation of neurons from astroglial stem cells in the adult SEZ (Hack et al., 2005). Remarkably, postnatal astroglia can be redirected toward neurogenesis by forced expression of Pax6 in vitro (Heins et al., 2002). Finally, in a stab wound lesion model, transduction of proliferative glia with Pax6 can induce expression of early neuronal markers in some cells (Buffo et al., 2005). However, it is not known whether these neurons are also functional, nor has their specific neuronal phenotype been investigated.

Therefore, we set out to determine here the physiological properties of neurons derived from astroglial cells. Moreover, we asked whether astroglial cells can be reprogrammed toward distinct neuronal identities. Because the generation of distinct neuronal phenotypes has been shown to be induced by different neurogenic fate determinants (Guillemot, 2005), we first examined here whether the proneural genes neurogenin-2 (Ngn2), and Mash 1 (mammalian achaete-schute homolog 1) can instruct early postnatal cortical astroglial cells to adopt a neuronal iden- 
tity as described previously for Pax6 (Heins et al., 2002). These factors attracted our attention because they can instruct a glutamatergic versus GABAergic fate in precursors of the developing forebrain (Guillemot, 2005) as well as in neural stem cells from the adult subependymal zone in vitro (Berninger et al., 2007). Here we demonstrate that these TFs do indeed possess the capacity to reprogram astroglial cells toward a neuronal identity and then show by patch-clamp recording that astroglial cells reprogrammed by Ngn2, Mash1, or Pax6 do acquire true neuronal properties such as intrinsic excitability and the ability to generate typical neuronal action potentials (APs).

\section{Materials and Methods}

Cell culture, retroviral transduction, and immunocytochemistry. For culturing postnatal astroglia, we followed the procedure described by Heins et al. (2002). Tissue from postnatal day 5 (P5) to P7 cerebral cortex of C57BL/6 mice was dissected and dissociated mechanically. Subsequently, cells were centrifuged for $5 \mathrm{~min}$ at $1000 \mathrm{rpm}$ and plated in a medium consisting of DMEM/F-12 (Invitrogen, Carlsbad, CA), 3.5 mm glucose (Sigma, St. Louis, MO), 10\% fetal calf serum (Invitrogen), 5\% horse serum (Invitrogen), and penicillin/streptomycin (Invitrogen) and supplemented with B27 (Invitrogen), $10 \mathrm{ng} / \mathrm{ml}$ epidermal growth factor (Roche, Indianapolis, IN) and $10 \mathrm{ng} / \mathrm{ml}$ fibroblast growth factor 2 (Roche). Cells were passaged after 1 week using trypsin/EDTA (Invitrogen) and plated on poly-D-lysine-coated coverslips at a density of 80,000 cells per well (24-well plates) in the same medium. For some experiments, bromodeoxyuridine (BrdU) at $10 \mu \mathrm{m}$ was added in the first $24 \mathrm{~h}$. The vast majority of cells $(>90 \%)$ in these cultures were positive for glial fibrillary acidic protein (GFAP), as were most of the BrdU-positive cells $(88.6 \%)$ (supplemental Fig. 1, available at www.jneurosci.org as supplemental material). Retroviral transduction was performed $2-3 \mathrm{~h}$ after plating using vesicular stomatitis virus $G$ protein (VSV-G) pseudotyped retroviruses containing the CMMP plasmid for control or containing Pax6-internal ribosomal entry site (IRES)-green fluorescent protein (GFP) (Hack et al., 2004), Ngn2-IRES-GFP, or Mash1-IRES-GFP (Hatakeyama et al., 2001; Berninger et al., 2007), respectively. Twentyfour hours after transduction, the medium was completely replaced by a medium consisting of DMEM/F-12, 3.5 mM glucose, penicillin/streptomycin, B27 supplement, and $20 \mathrm{ng} / \mathrm{ml}$ brain-derived neurotrophic factor (BDNF; Chemicon, Eagle Close, UK). For coculture experiments, either embryonic day 14 (E14) or E16 cerebral cortices were dissected and dissociated with trypsin, and cells were added to the glial culture $1 \mathrm{~d}$ after transduction of the astrocytes. Before adding neurons, astroglial cultures were washed with PBS to remove remaining active viral particles in the medium. To confirm that subsequently added cortical neurons were not transduced, we verified that no GFP-positive neurons were encountered when astroglial precursors had been transduced with the GFP control virus $1 \mathrm{~d}$ before. In those experiments in which E14 cortical precursors were transduced, cells were incubated together with retroviral particles in suspension for $30 \mathrm{~min}$ before plating.

At 1-32 d after transduction, cells were used for either electrophysiology or immunocytochemistry. The number of days after retroviral transduction is indicated as days post infection (DPI). Because in the initial phase of the electrophysiological studies we failed to observe spontaneous synaptic activity nor could we detect autaptic connections $(n=15)$, we added $20 \mathrm{ng} / \mathrm{ml}$ BDNF every fourth day during differentiation to the cultures because it has been shown that neurons derived from neural stem cells require BDNF for robust synapse formation (Song et al., 2002). In some cases, we added neurotrophin-3 (NT-3; Chemicon) instead of BDNF.

For immunocytochemistry, cultures were fixed in 4\% paraformaldehyde in PBS for $15 \mathrm{~min}$ at room temperature and processed for antibody staining as described previously (Hartfuss et al., 2001). Primary antibodies [anti-GFP (mouse IgG1, at 1:500; Chemicon), anti- $\beta$-III-tubulin (TuJ1) (mouse IgG2b, at 1:100; Sigma), anti-Tbr1 (T-box brain gene 1) (rabbit, at 1:1000; Chemicon), anti-BrdU (rat, at 1:100; Abcam, Cambridge, CA) (pretreatment with $30 \mathrm{~min}$ of $2 \mathrm{~N} \mathrm{HCl}, 30 \mathrm{~min}$ of borate buffer, $\mathrm{pH}$ 8.5), anti-GFAP (mouse IgG1, at 1:200; Sigma), anti-O4 (mouse IgM, at 1:200; provided by J. Price, King's College, London, UK), anti-NG2 (rabbit, at 1:250; Chemicon), and anti-Ngn2 (mouse IgG12a, at 1:10; provided by D. Anderson, California Institute of Technology, Pasadena, CA)] were incubated overnight at $4^{\circ} \mathrm{C}$ and detected by subclass-specific secondary antibodies labeled with FITC or tetramethylrhodamine isothiocyanate.

Time-lapse video microscopy. Postnatal astroglia from human GFAP (hGFAP)-GFP and wild-type (WT) mice (Nolte et al., 2001) were mixed at 1:1 ratio to allow visualization of individual GFP-positive astrocytes and were cultured as described above. Twenty hours after retroviral infection and $2 \mathrm{~h}$ after medium replacement, the tissue culture plate was tightly sealed and time-lapse microscopy was performed with a cell observer (Zeiss, Oberkochen, Germany) at a constant temperature of $37^{\circ} \mathrm{C}$. Phase-contrast pictures of control (six positions, two coverslips) and Ngn2 transduced cells (13 positions, three coverslips) were acquired every $2 \mathrm{~min}$ and fluorescent pictures every $3 \mathrm{~h}$ for $7 \mathrm{~d}$ with Axiovision release 4.5 software (Zeiss) and an AxioCam HRm camera, according to the instructions of the manufacturer. Images were assembled into a movie and analyzed using Axiovision release 4.5 and MetaMorph Offline (version 6.1r4; Molecular Devices, Palo Alto, CA) software. hGFAPGFP-positive cells were distinguished from WT astroglia by fluorescence at the beginning of the time-lapse series, and their lineage was followed in phase contrast until the last time point before fixation. After immunostaining for TuJ1, Ngn2, and GFP, the positions in the time lapse were matched, and neuronal cells were tracked backwards to identify their cell of origin.

Electrophysiology. Single or dual perforated patch-clamp recordings (Horn and Marty, 1988; Rae et al., 1991) were performed at room temperature with amphotericin-B (Calbiochem, La Jolla, CA) for perforation. Micropipettes were made from borosilicate glass capillaries. $\mathrm{Pi}$ pettes were tip filled with internal solution and backfilled with internal solution containing $200 \mu \mathrm{g} / \mathrm{ml}$ amphotericin-B. The electrodes had resistances of $2-2.5 \mathrm{M} \Omega$. The internal solution contained the following (in mM): $136.5 \mathrm{~K}$-gluconate, $17.5 \mathrm{KCl}, 9 \mathrm{NaCl}, 1 \mathrm{MgCl}_{2}, 10 \mathrm{HEPES}$, and 0.2 EGTA, pH 7.4 (at an osmolarity of $300 \mathrm{mOsm}$ ). The external solution contained the following (in $\mathrm{mm}$ ): $150 \mathrm{NaCl}, 3 \mathrm{KCl}, 3 \mathrm{CaCl}_{2}, 2 \mathrm{MgCl}_{2}, 10$ HEPES, and 5 glucose, pH 7.4 (at an osmolarity of $310 \mathrm{mOsm}$ ). The recording chamber was continuously perfused with external solution at a rate of $0.5 \mathrm{ml} / \mathrm{min}$. Cells were visualized with a Zeiss Axioskop2. Signals were sampled at $10 \mathrm{kHz}$ with Axopatch 200B patch-clamp amplifiers (Molecular Devices), filtered at $5 \mathrm{kHz}$, and analyzed with Clampfit 9.2 software (Molecular Devices). For determining input resistances, hyperpolarizing currents of small amplitudes were injected into the cells under current-clamp condition at a holding potential of $-70 \mathrm{mV}$, and input resistances were calculated from the corresponding voltage deviation. For assessing the ability of a cell to fire action potentials, cells received depolarizing step-current injections. Action potential amplitudes were measured by subtracting the threshold voltage of the action potential from the absolute voltage amplitude.

Sodium currents were determined in voltage clamp by subtracting the current response after a step depolarization from -70 to $-45 \mathrm{mV}$ in the presence of $0.5 \mu \mathrm{M}$ tetrodotoxin (TTX) from the corresponding trace under control conditions. To examine spontaneous synaptic input into a given neuron, cells were kept in voltage clamp at a holding potential of $-70 \mathrm{mV}$, and events were recorded throughout a period of $1-5 \mathrm{~min}$. To assess autaptic connections, single cells were step depolarized in voltage clamp for $1 \mathrm{~ms}$ from -70 to $+30 \mathrm{mV}$, and responses were recorded in the same cell. Responses were considered to be autaptic when they occurred within $3 \mathrm{~ms}$ after the step depolarization (Fitzsimonds et al., 1997). Synaptic connectivity was investigated by means of pair recordings in voltage-clamp mode. One neuron was stimulated at low frequency $(0.05-0.1 \mathrm{~Hz})$ by a $1 \mathrm{~ms}$ step depolarization from -70 to $+30 \mathrm{mV}$, and the response was recorded from the other neuron and vice versa.

\section{Results}

\section{Reprogramming of cortical astroglial cells by Ngn2 and Mash 1}

In an initial series of experiments, we examined whether early postnatal astroglia can be reprogrammed by forced expression of 


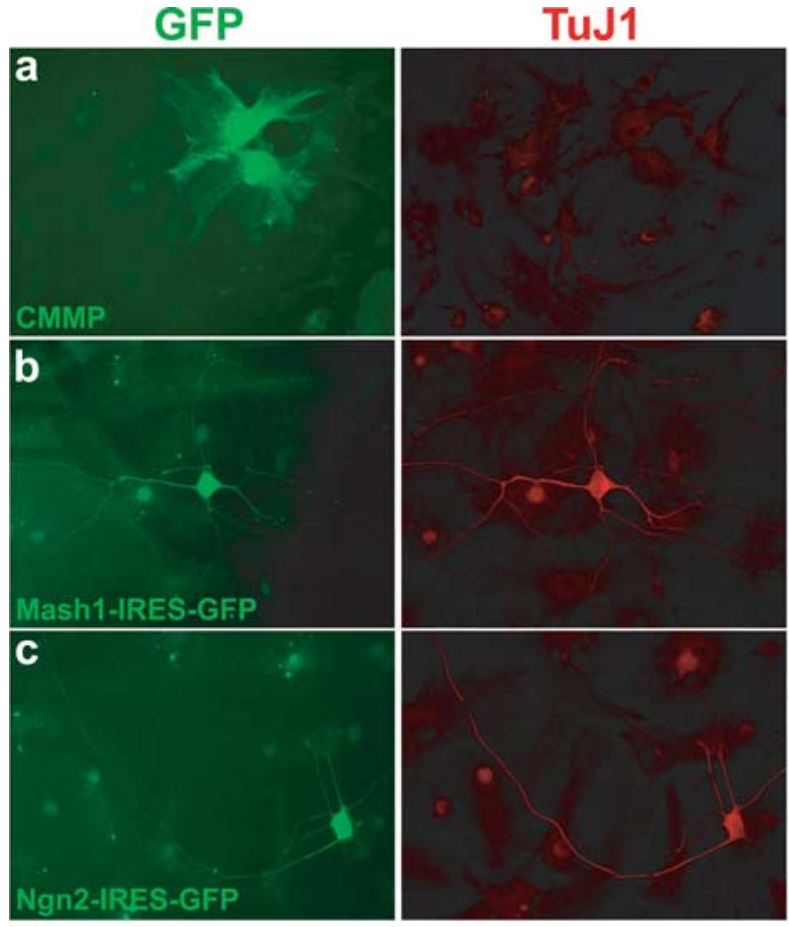

d

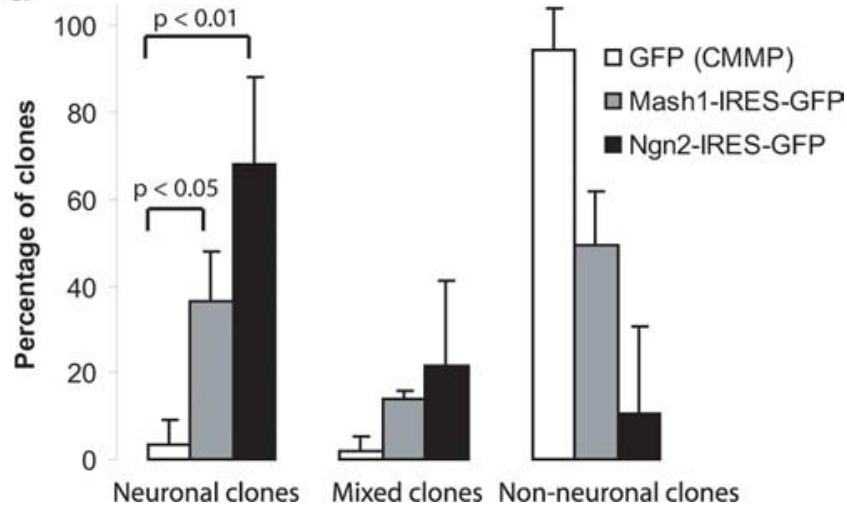

Figure 1. Ngn2 and Mash 1 can reprogram astroglial cells to adopt a neuronal fate. $\boldsymbol{a}$, Examples of astroglia transduced with a vector only encoding GFP (CMMP) $12 \mathrm{~d}$ after infection. Left, GFP immunoreactivity; right, TuJ1 immunoreactivity. $\boldsymbol{b}$, Example of Mash1-transduced cell also positive for TUJ1 $12 \mathrm{~d}$ after infection. c, Example of Ngn2-transduced cell double-positive for TUJ1 $12 \mathrm{~d}$ after infection. $\boldsymbol{d}$, Summary of three independent experiments in which the number of clones consisting of TuJ1-positive (neuronal), TuJ1-positive as well as -negative (mixed), and only TuJ1-negative (non-neuronal) cells is given as a percentage of all clones analyzed. Cells were fixed $12 \mathrm{~d}$ after infection and analyzed in three different experimental batches with $>100$ cells counted in each batch. For statistical analysis, a nonparametric ANOVA was used with a Dunn's post hoc analysis.

the proneural genes Ngn2 and Mash1 like has been described previously for Pax6 (Heins et al., 2002). Astroglial cells were prepared from P5-P7 mouse cerebral cortex and cultured in serum containing medium (see Material and Methods). After 1 week, cells were passaged, subsequently transduced with VSV-G pseudotyped Moloney-based retroviral vectors encoding GFP, Ngn2-IRES-GFP or Mash1-IRES-GFP (Hatakeyama et al., 2001; Hack et al., 2004; Berninger et al., 2007), and assayed $12 \mathrm{~d}$ after transduction by immunostaining for the early neuronal marker TuJ1 (Fig. 1). The retroviral gene transfer ensured that all cells included in the analysis had been generated from cells proliferating in vitro, thus excluding contaminating postmitotic neu-

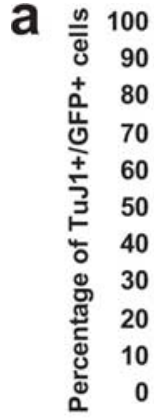

$\begin{array}{ccccc}\text { IRES- } & \text { IRES- } & \text { Ngn2- } & \text { Ngn2- } & \text { Ngn2- } \\ \text { GFP 1d } & \text { GFP 7d } & \text { GFP } & \text { GFP } & \text { GFP } \\ & & \text { 1d } & \text { 4d } & \text { 7d }\end{array}$
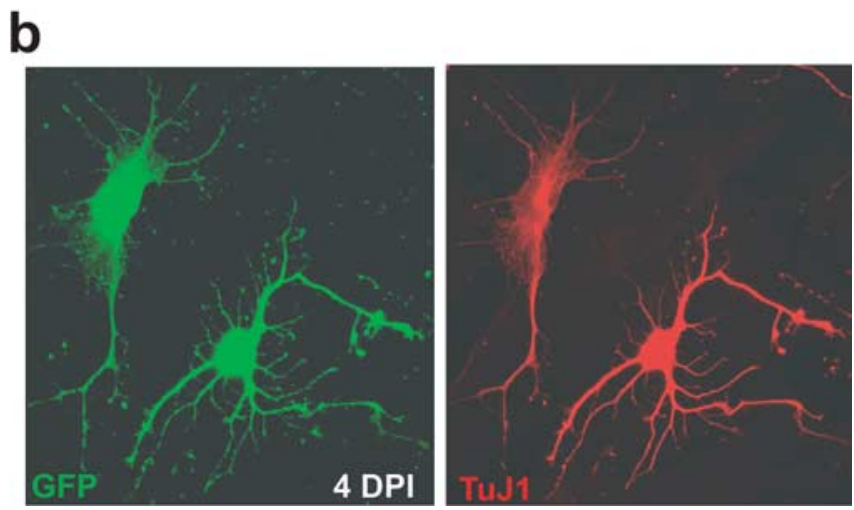

Figure 2. Gradual acquisition of neuronal markers by cells of astroglial origin during reprogramming with Ngn2. a, Time course of TuJ1 immunoreactivity in astroglial cultures transduced with Ngn2. $\boldsymbol{b}$, Example of two cells expressing Ngn2-IRES-GFP (green, left) $4 \mathrm{~d}$ after transduction. Both cells express TuJ1 (red, right). Note the partially astroglial morphology of the left cell indicating a transitional state.

rons from our analysis. After transduction with the retroviral vector encoding GFP only, a negligible number of clones (progeny of a single infected cell) contained TuJ1-positive neurons (Fig. 1a,d). In pronounced contrast, transduction with Mash1 resulted in $37 \pm 11 \%$ clones containing exclusively TuJ1-positive neurons and $14 \pm 2 \%$ containing both TuJ1-positive and -negative cells (Fig. 1b,d). The neurogenic effect of Ngn2 transduction was even more striking, with $71 \pm 16 \%$ of clones comprising only TuJ1-immunoreactive neuronal cells and $16 \pm 18 \%$ containing a mixed population of both TuJ1-positive and -negative progeny $12 \mathrm{~d}$ after transduction with the Ngn2containing virus (Fig. $1 c, d$ ). Thus, $>85 \%$ of the transduced astroglial cells gave rise to progeny with a neuronal identity.

To examine the reprogramming process in more detail, we followed the gradual acquisition of neuronal traits over time after transduction with Ngn2. Notably, $1 \mathrm{~d}$ after transduction, none of the GFP-positive cells in the control or the Ngn2-transduced cultures were $\mathrm{TuJ} 1$ positive. However, whereas in the control no GFP/TuJ1 double-positive cells were found after $7 \mathrm{~d}$, after transduction with Ngn2 a substantial portion $(26 \pm 11 \%)$ of the GFPpositive cells had become TuJ1 immunoreactive after $4 \mathrm{~d}$ and further increased to $77 \pm 11 \%$ by day 7 (Fig. $2 a$; three independent experiments, with $>100$ transduced cells being analyzed per single experiment and each time point). Interestingly, some of the GFP/TuJ1 double-positive cells exhibited still a transitional morphology $4 \mathrm{~d}$ after transduction (Fig. 2b).

The relatively high purity of our culture system $(>95 \%$ of astroglial cells as assessed by GFAP immunoreactivity) (supplemental Fig. $1 a, b$, available at www.jneurosci.org as supplemental 


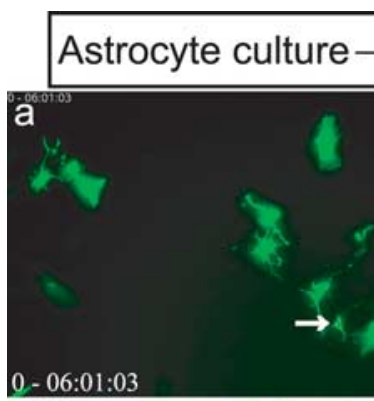

$2 \mathrm{~h}$ Retroviral infection

\section{$\stackrel{20 \mathrm{~h}}{\longrightarrow}$ Time lapse}
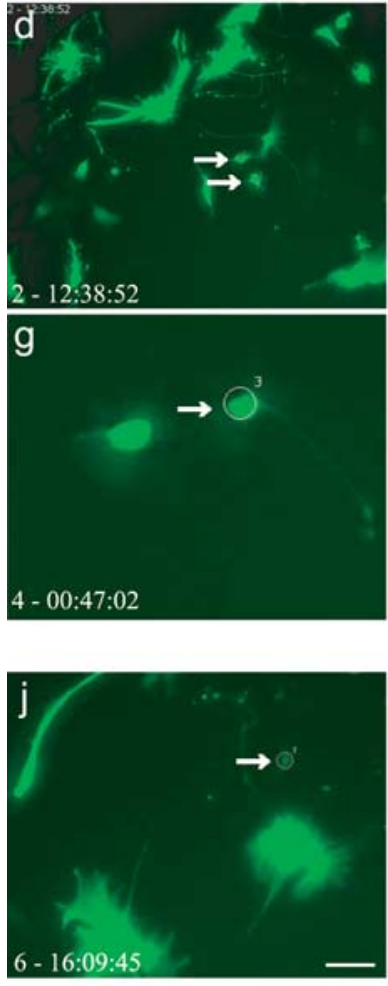
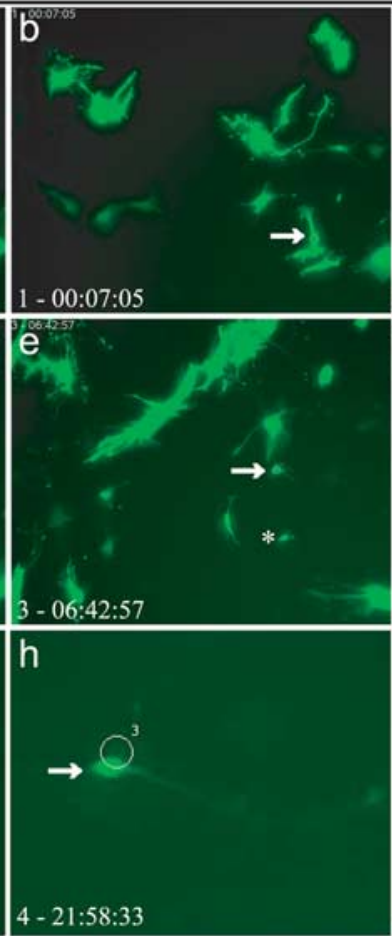

GFP TUJ1 Ngn2

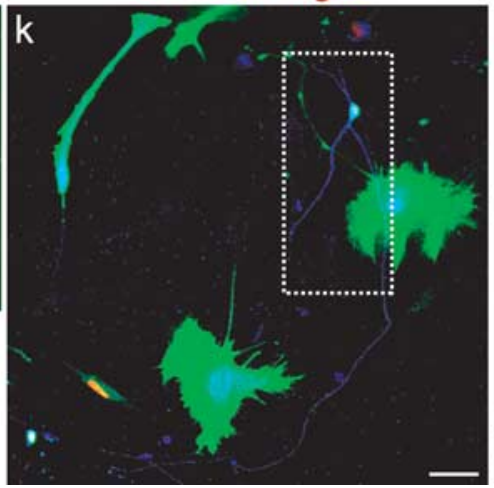

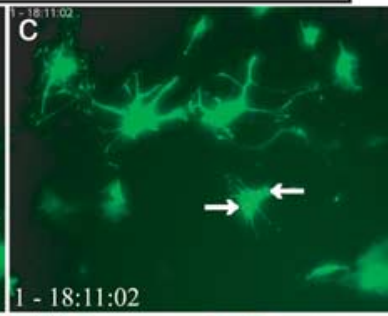
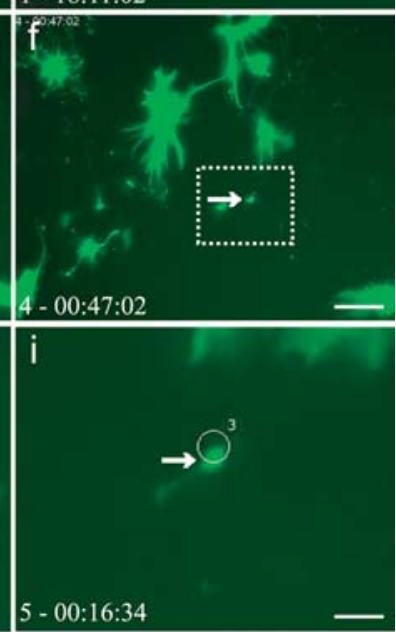

TUJ1 Ngn2

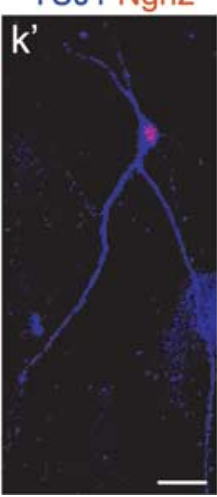

Figure 3. Time-lapse video microscopy of hGFAP-GFP-positive cells transforming into neurons after Ngn2 transduction. $\boldsymbol{a}-\boldsymbol{j}$, Time-lapse images of an astroglia culture derived from a P7 hGFAP-GFP transgenic mouse after transduction with Ngn2. Arrows point to an GFP-positive astroglial cell at an early stage when virally mediated GFP expression is not yet detectable $(\boldsymbol{a}, \boldsymbol{b})$. The progeny of this cell is delineated by two arrows $(\boldsymbol{c}, \boldsymbol{d})$ shortly after cell division. The daughter cell depicted by an asterisk $(\boldsymbol{e})$ then undergoes cell death, whereas the remaining cell (depicted at higher power in $\boldsymbol{g}$-j) underwent a marked change in cell morphology, displaying neuronal-like characteristics (arrows in $f-j$ ). The corresponding time is indicated in the left corner of each image (in days-hours:minutes:seconds). Box in $\boldsymbol{f}$ is amplified in $\boldsymbol{g}$-i. $\boldsymbol{k}, \boldsymbol{k}^{\prime}$, After imaging, cells were fixed and immunocytochemically analyzed for GFP (green), Tuj1 (blue), and Ngn2 (red). The neuronal identity of the reprogrammed cell was confirmed by its immunoreactivity for TuJ1. Box in $\boldsymbol{k}$ is shown at higher magnification in $\boldsymbol{k}^{\prime}$. Note the Ngn2 immunoreactivity in the nucleus, confirming that the neuron was derived from a Ngn2-transduced cell. Scale bars: $\boldsymbol{a}-\boldsymbol{f}, \boldsymbol{j}, 120 \mu \mathrm{m} ; \boldsymbol{k}, 50 \mu \mathrm{m} ; \boldsymbol{g}-\boldsymbol{i}, 30 \mu \mathrm{m} ; \boldsymbol{k}^{\prime}, 25 \mu \mathrm{m}$.

material) suggests that the surprisingly high number of cells exhibiting a neuronal phenotype after Mash1 or Ngn2 transduction indeed had been generated mostly by cells of astroglial origin. To confirm that astroglial cells were the main target of the retroviral transduction, we first analyzed how many of the cells undergoing S-phase during the first $24 \mathrm{~h}$ were also GFAP positive by adding the thymidine analog BrdU for $1 \mathrm{~d}$ to the cultures after passaging. Eighty-nine percent of the cells incorporating BrdU were also GFAP positive, whereas of the remaining, $10 \%$ were NG2 and $1 \%$ were $\mathrm{TuJ} 1$ positive (supplemental Fig. $1 c, d$, available at www. jneurosci.org as supplemental material). Indeed, also $84 \pm 1 \%$ of the GFP-positive cells after transduction with control virus encoding GFP only the day before were also GFAP immunoreactive (three independent experiments, with $>100$ transduced cells being analyzed) (supplemental Fig. 1e, available at www. jneurosci.org as supplemental material), thus indicating that the majority of virally transduced cells is indeed astroglia $(>80 \%)$, most of which progress toward a neuronal differentiation after Ngn2 transduction (70\%).

Although this high rate of neurogenesis from virally transduced astroglia is difficult to explain by selective expansion of the few transduced cells that were not astroglia, we still aimed to examine the progression from astroglia to neuron after Ngn2 transduction by live imaging using time-lapse video microscopy of astroglial cultures prepared from transgenic mice expressing GFP under the control of the human GFAP promoter (Nolte et al., 2001). Human GFAP-GFP-positive cells were identified by their strong fluorescence at the beginning of the time-lapse experiments (Fig. 3) (supplemental Movies 1-3, available at www.jneurosci.org as supplemental material), whereas virally mediated expression of GFP became detectable only after $\sim 48 \mathrm{~h}$, thus permitting the unambiguous identification of cells expressing GFP under the control of the hGFAP promoter. Control astroglia typically underwent several rounds of cell division and generated GFP-positive/TuJ1-negative progeny (Supplemental Movie 3 available at www.jneurosci.org as supplemental material). In sharp contrast, after transduction with Ngn2 hGFAP-GFP-positive cells were found to exit cell cycle after one round of division and then differentiated into TuJ1-positive cells (Fig. 3) (supplemental Movies 1, 2, available at www. jneurosci.org as supplemental material). Remarkably, the example shown in Figure 3 revealed that, whereas one daughter cell gradually acquired a neuronal morphology, the other daughter cell died, presumably by apoptosis. The acquisition of a neuronal morphology at day 4 after transduction coincided with the onset of TuJ1 expression in these cultures (Fig. 2). Subsequent immunocytochemistry confirmed that the surviving daughter cell exhibiting a neuronal morphology was indeed $\mathrm{Tu} 1 \mathrm{l}$ positive and also expressed Ngn2 (Fig. $3 k^{\prime}$ ). These experiments provide unequivocal evidence that cells with astroglial identity can be reprogrammed by neurogenic fate determinants.

\section{Reprogramming of astroglial cells by Ngn 2 involves} upregulation of the T-box transcription factor Tbr1

To assess whether Ngn2 and Mash1 do not only exert a neurogenic effect in astroglial cells but can also direct their fate toward 
distinct neuronal subtype lineages, we first investigated whether neurons could be stained for either GABA or the vesicular glutamate transporter-1. However, at $12 \mathrm{~d}$ after infection, no strongly immunopositive cells were observed, suggesting that transmitter maturation may not be fully completed (data not shown). Thus, we turned to an earlier marker of glutamatergic cortical neurons, the T-box TF Tbr1 that is known to be expressed transiently in virtually all telencephalic glutamatergic neurons during development and to be retained in specific subpopulations of glutamatergic neurons in the adult cerebral cortex and hippocampus (Hevner et al., 2006). One day after forced expression of Ngn2, no Tbr1/GFP double-positive cells were found (Fig. 4a,d). However, 3 d later, a small subpopulation of GFP-positive cells (8\%) expressed Tbr1 (Fig. 4b,d). By day 7 , approximately one-third of the GFP cells were Tbr1 immunoreactive (Fig. $4 c, d)$. In contrast, neither after control (Fig. 4d,f) nor Mash1 (Fig. 4d,e) transduction were any Tbr1/GFP double-positive cells encountered, demonstrating that Tbr1 upregulation is specific to reprogramming by Ngn2. We also attempted to elucidate the specificity of neurons derived from Mash1-transduced astroglial cells by immunostaining with Dlx2 (distal-less homeobox 2), a transcription factor known to be expressed in interneurons of telencephalic origin (Anderson et al., 1999) and a direct target of Mash1 (Poitras et al., 2007). Whereas after forced expression of Dlx2 astroglial cells exhibited a clear nuclear staining for Dlx2, no such staining was detected in neurons derived from either Mash1- or Ngn2-transduced cells (data not shown).

\section{Neurons derived from reprogrammed astroglia fire action potentials}

In the next set of experiments, we examined whether astroglial cells transduced with neurogenic fate determinants, besides adopting morphological and immunocytochemical neuronal characteristics, also acquire the electrophysiological hallmarks of neurons, such as the ability of

(repetitive) AP firing. To this end, we performed patch-clamp recordings of astroglia-derived cells transduced with Ngn2IRES-GFP, Mash1-IRES-GFP, or Pax6-IRES-GFP, which has been shown previously to reprogram astroglial cells toward a neuronal fate (Heins et al., 2002). Figure $5 a-c$ shows examples of neurons derived from reprogrammed astroglial cells cultured for $>2$ weeks after infection. In all of these cells, current injection resulted in a repetitive discharge of APs. The discharge pattern was quite similar to that of neurons derived from E14 cortical precursors transduced with the control GFP virus (Fig. $5 d$ ). The ability to spike correlated with the presence of a substantial negative.

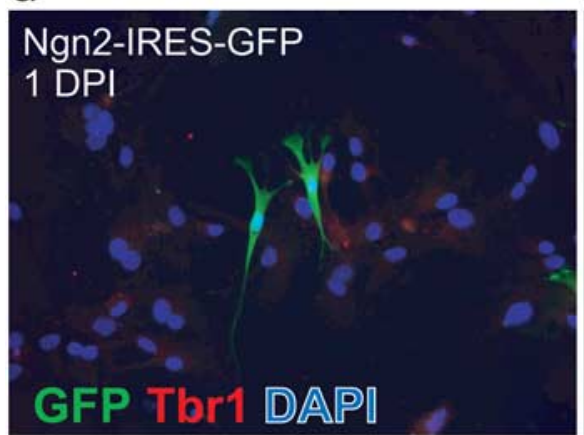

b

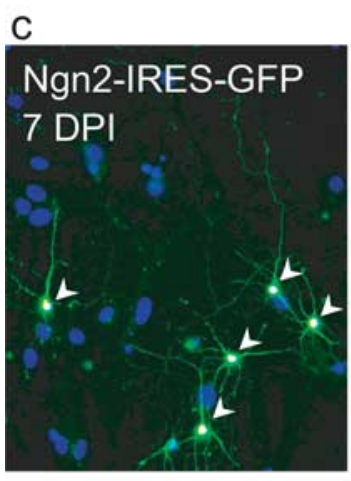

$\mathrm{c}^{\prime}$

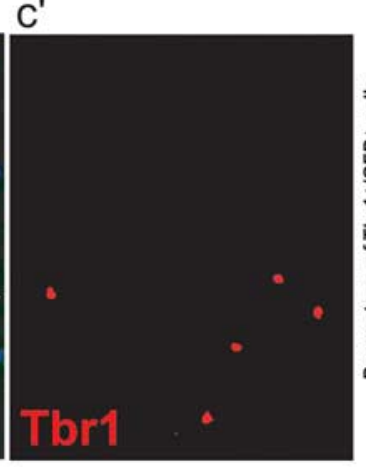

d
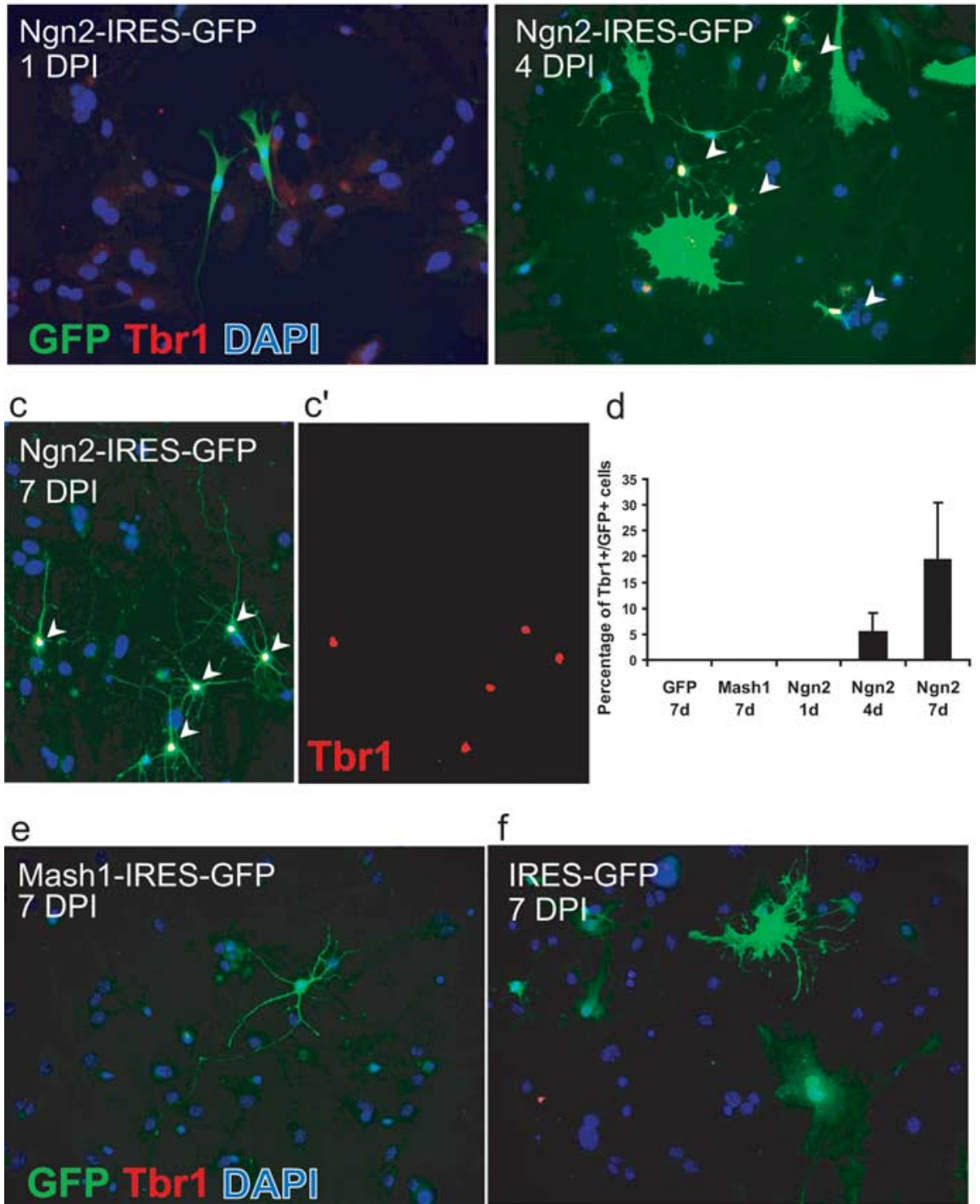

Figure 4. Upregulation of the T-box transcription factor Tbr1 after reprogramming of astroglial cells by Ngn2 but not Mash1. $\boldsymbol{a}-\boldsymbol{c}$, Representative images taken at discrete stages of maturation after transduction with Ngn2. $\boldsymbol{a}$, Depicted are two GFP-positive (green)/Tbr1-negative (red) cells $1 \mathrm{~d}$ after transduction with Ngn2-IRES-GFP. $\boldsymbol{b}$, By day 4, some Ngn2-expressing cells with a neuroblast morphology exhibit Tbr1 immunoreactivity (white nuclei depicted by arrowheads). c, $\mathbf{c}^{\prime}$, By day 7, an additional increased number of Ngn2-transduced cells is also Tbr1 positive (white nuclei indicated by arrowheads in c and red nuclei in $c^{\prime}$ ). Most of these cells now display a distinctly neuronal morphology. Cells were stained for GFP (green) to visualize transduced cells, Tbr1 (red), and 4' ,6' -diamidino-2-phenylindole (DAPI) to identify nuclei. $\boldsymbol{d}$, Quantification of Tbr1-positive cells after transduc stages no Tbr1 immunoreactivity was found. In the case of Ngn2, a gradual increase in the number of Tbr1-positive cells was noted.

voltage-dependent $\mathrm{Na}^{+}$current, and APs were blocked by the voltage-dependent $\mathrm{Na}^{+}$channel blocker TTX (Fig. 5). In pronounced contrast to astroglial cells reprogrammed by neurogenic fate determinants, astroglia transduced with a GFP-containing control virus (CMMP) exhibited current-voltage relationships that resulted in linear curves $(n=14)$ typical of mature astroglial cells (Fig. 6).

Figure 7 illustrates the transition from passive astroglial to active neuronal electrophysiological properties of reprogrammed astroglial cells. Four days after transduction with Ngn2, reprogrammed astroglial cells exhibited essentially passive current- 
a
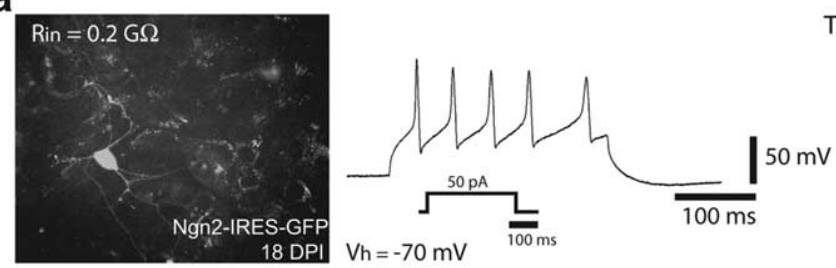

TTX sensitive component

b
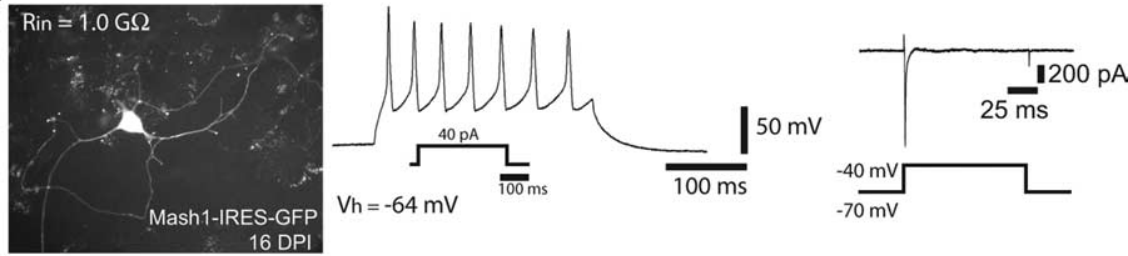

C
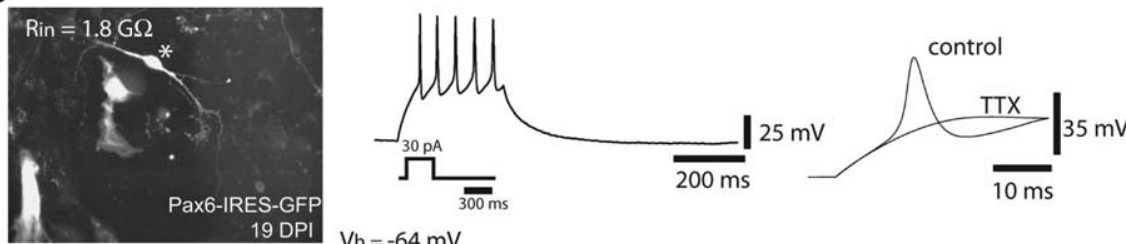

d

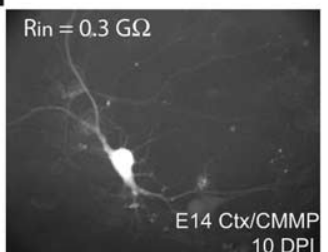

$10 \mathrm{DPI}$

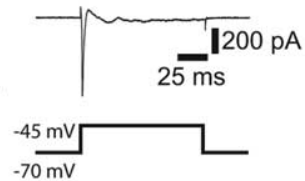

$-70 \mathrm{mV}$
$\mathrm{Vh}=-64 \mathrm{mV}$

Figure 5. Astroglial cells reprogrammed by neurogenic fate determinants fire action potentials. $\boldsymbol{a}$, Example of a neuron derived from an astroglial cell reprogrammed by Ngn2 18 DPI. Left shows cell expressing Ngn2-IRES-GFP. Step current injection (50 pA for $300 \mathrm{~ms}$ ) in current clamp resulted in repetitive firing of action potentials (middle). The right shows the TTX-sensitive $\mathrm{Na}{ }^{+}$ current induced by step depolarization from -70 to $-45 \mathrm{mV}$. The trace shown was obtained by subtracting the current response in the presence of $1 \mu \mathrm{M}$ TTX from the control trace. $\boldsymbol{b}$, Example of a neuron derived from an astroglial cell reprogrammed by Mash1 (16 DPI). Left shows expression of GFP after transduction with Mash1-IRES-GFP. The middle shows the repetitive discharge of action potentials in response to current injection in current clamp. The right shows the TTX-sensitive $\mathrm{Na}^{+}{ }^{+}$current activated by step depolarization from -70 to $-40 \mathrm{mV}$. c, Example of a neuron (marked by asterisk) derived from an astroglial cell reprogrammed by Pax6. The left shows expression ofGFP after transduction with Pax6-IRES-GFP. The middle shows the repetitive spiking behavior of the cell after current injection. The right shows that action potentials were blocked by $1 \mu \mathrm{M}$ TTX. $\boldsymbol{d}$, Example of a neuron derived from embryonic cortex and transduced with a control vector encoding GFP only (CMMP). The cell exhibited a repetitive firing in response to current injection in current clamp. $V_{\mathrm{h}}$ indicates the membrane potential at which the cells had been kept.
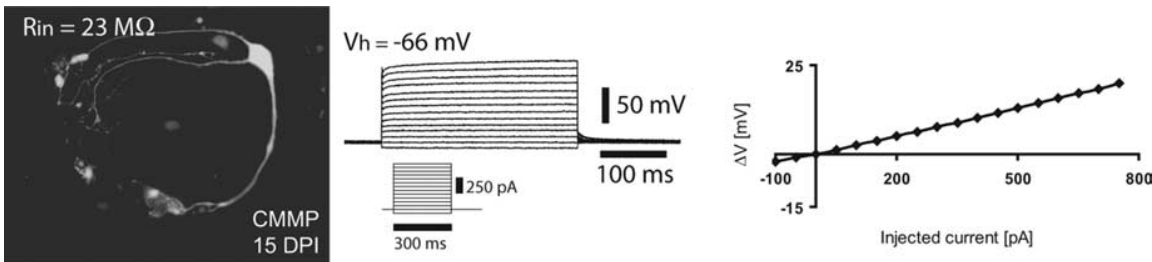

Figure 6. Control GFP virus-transduced astroglia do not fire action potentials. Example of a cell transduced with virus containing only GFP (see micrograph; for construct, see Materials and Methods), exhibiting a linear current-voltage relationship. Middle shows a family of membrane potentials in response to step current injection. Right shows voltage changes in response to current injection.

voltage relationships (Fig. $7 a$, right), and no spike or spikelet could be evoked by step depolarization (Fig. $7 a$, middle). Two days later, reprogrammed cells were found to exhibit small spikelets, and their appearance correlated with the presence of small
TTX-sensitive $\mathrm{Na}^{+}$current during step depolarization in voltage clamp (Fig. 7b), yet the current-voltage relationship was still fairly passive (Fig. $7 b$, right). After additional time in culture, Ngn2-expressing cells started to fire single APs in response to current injection (Fig. $7 c$, left) and the current-voltage relationship exhibited a steeper outward rectification, i.e., a decreased input resistance at depolarized potentials, most likely attributable to an increased activation of $\mathrm{K}^{+}$current compared with the previous stages (Fig. $7 c$, right). At this developmental stage, the TTX-sensitive $\mathrm{Na}^{+}$current evoked by step depolarization was further increased (Fig. $7 c$ ). At even later stages, neurons started to fire more than one AP, eventually becoming repetitively firing (Figs. $5 a, 7 d$ ) (supplemental Fig. 2, available at www. jneurosci.org as supplemental material). This spiking behavior was accompanied by an additional increase in TTX-sensitive $\mathrm{Na}^{+}$current (Figs. 5a, 7d) and a substantial outward rectification (Fig. $7 d$, right). At that stage, neurons often exhibited spike adaptation and accommodation (supplemental Fig. 2, available at www.jneurosci.org as supplemental material).

The progressive maturation of the astroglia-derived neurons became also evident from a decrease in the resting membrane potential and input resistance, as well as an increase in AP amplitude over time in culture (Table 1). For all three different TFs, neurons arising from reprogrammed astroglia developed more negative resting membrane potentials with time (Table 1). Likewise, input resistances decreased significantly in astrogliaderived neurons with the age of the cells (Table 1). Conversely, AP amplitudes increased significantly between the first and the second week in culture (Table 1). Interestingly, when astroglia-derived neurons were compared with age-matched embryonic cortical neurons after 14-20 d in culture, input resistances of the astroglia-derived neurons were significantly larger (Table 1). This may indicate that astroglia-derived neurons mature somewhat slower than embryonic neurons. However, input resistances varied greatly within a given age group, suggesting that the pace of maturation is highly heterogeneous. Thus, individual astrogliaderived neurons reached a maturational stage similar to cortical neurons with fairly low input resistances and comparable resting potential and AP amplitudes (for instance, see the example shown in Fig. 5a), and, after 3 weeks in culture, none of the parameters studied were significantly different between astrogliaderived and embryonic cortical neurons. 
Lack of evidence for synapse formation by astroglia-derived neurons

Next we assessed the ability of neurons derived from reprogrammed astroglia of forming synapses. Conspicuously, recordings of reprogrammed cells $(n=55$; data pooled from Pax6, Mash1, or Ngn2 reprogrammed cells) in voltage clamp revealed the virtual absence of spontaneous synaptic input (supplemental Fig. $3 a$, available at www.jneurosci.org as supplemental material). In only one anecdotal case did we observe one spontaneous synaptic event in a reprogrammed cell (supplemental Fig. $3 b$, available at www.jneurosci.org as supplemental material). To rule out the possibility that the failure of observing synaptic responses may have been attributable to a very low probability of spontaneous release, we examined whether autaptic responses could be evoked from neurons derived from reprogrammed astroglial cells. We tested for the presence of autapses by step depolarization from a holding potential of -70 to $+30 \mathrm{mV}$. For comparison, we studied autaptic responses in cultures of E14 cerebral cortical neurons derived from progenitors transduced in vitro with a GFP encoding control retrovirus (CMMP). Autaptic responses could be readily evoked in a substantial fraction of the recorded neurons (10 of 14) from E14 cortex cultures (Fig. 8b,c). E14 cortical autaptic responses were glutamatergic because they could be blocked by the AMPA/ kainate receptor antagonist CNQX (Fig. $8 b, d)$. This is consistent with the fact that the vast majority of cells generated in the embryonic cerebral cortex are glutamatergic neurons. In some cases, evoked responses of a polysynaptic nature that included GABAergic connections were also observed as indicated by their relatively long delay ( $>5 \mathrm{~ms}$ ) and block both by CNQX and bicuculline (data not shown).

Thus, our data demonstrates that embryonic neurons readily form autapses under these culture conditions. In contrast, in none of the astroglia-derived neurons did we observe any evoked response after step depolarization (Fig. $8 a, c$ ). To rule out the possibility that the lack of responses in reprogrammed cells was attributable to a peculiarity of autaptic connections, we also performed dual recordings from astroglia-derived neurons in coculture with embryonic cortical neurons. In none of the cases analyzed $(n=10)$ did we observe a synaptic response in the neighboring cortical neuron after current injection into the neuron derived from a reprogrammed astroglial cell (supplemental Fig. $4 a$, available at www.jneurosci.org as supplemental material). In contrast, in four of seven pairs of embryonic cortical neurons synaptic responses could be evoked (supplemental Fig. $4 b$, available at www.jneurosci.org as supplemental material). Finally, we tested whether the absence of BDNF or the presence of NT-3 would promote synapse formation, but, also under these conditions, no spontaneous or evoked synaptic activity was observed in astroglia-derived neurons $(n=8$; data not shown).

Neurons derived from reprogrammed astroglial cells receive functional synaptic inputs from cocultured cortical neurons The lack of synaptic activity observed in astroglia-derived neurons may be attributable to a failure of establishing either a functional presynaptic or postsynaptic compartment or both. To distinguish between these possibilities, we investigated whether astroglial-derived neurons are recognized as synaptic targets by synapse formation competent neurons. To this end, we cocultured astroglial cells $1 \mathrm{~d}$ after transduction with Ngn2 or Pax6 with dissociated neurons from embryonic day 16 cerebral cortex (see Material and Methods). GFP-positive cells were then assessed for the presence of spontaneous synaptic input by recordings in voltage clamp ( $8-28 \mathrm{~d}$ after transduction). In parallel, we recorded from GFP-negative neurons derived from the embryonic cortex. We found that 53\% (9 of 17) of astroglia-derived 
Table 1. Properties of reprogrammed astroglia at discrete stages of maturation

\begin{tabular}{|c|c|c|c|c|}
\hline & $\mathrm{DPI}$ & $V_{\text {rest }}(\mathrm{mV})$ & $R_{\text {input }}(\mathrm{G} \Omega)$ & AP amplitude (mV) \\
\hline \multicolumn{5}{|c|}{ Astroglia-derived neurons } \\
\hline \multicolumn{5}{|c|}{ Total } \\
\hline$(n=38)$ & $7-13$ & $-50 \pm 18^{* *} 7$ & $\left.\left.\left.2.0 \pm 1.2^{* * *}\right]\right]_{*}\right]$ & $\left.44 \pm 20^{* *}\right]_{-* *}$ \\
\hline$(n=29)$ & $14-20$ & $-57 \pm 16 \quad{ }^{*}$ & $1.1 \pm 0.8^{*} \quad J^{*} L^{* *}$ & $61 \pm 18$ \\
\hline$(n=10)$ & $>20$ & $-69 \pm 21]$ & $0.8 \pm 0.6$ & $50 \pm 16$ \\
\hline \multicolumn{5}{|l|}{ Pax6 } \\
\hline$(n=13)$ & $7-13$ & $-41 \pm 237$ & $2.0 \pm 1.2^{* *}$ & $35 \pm 14^{* *}$ \\
\hline$(n=7)$ & $14-20$ & $-65 \pm 20 \quad L^{*}$ & $1.7 \pm 1.1$ & $44 \pm 16$ \\
\hline$(n=6)$ & $>20$ & $-73 \pm 21\rfloor$ & $0.9 \pm 0.3$ & $43 \pm 4$ \\
\hline \multicolumn{5}{|l|}{ Mash1 } \\
\hline$(n=8)$ & $7-13$ & $-56 \pm 5$ & $2.2 \pm 1.4^{* *}$ & $47 \pm 15$ \\
\hline$(n=6)$ & $14-20$ & $-62 \pm 14$ & $0.9 \pm 0.2$ & $74 \pm 10$ \\
\hline \multicolumn{5}{|l|}{$\operatorname{Ngn} 2$} \\
\hline$(n=17)$ & $7-13$ & $-55 \pm 16$ & $1.7 \pm 1.0^{*}$ & $50 \pm 25$ \\
\hline$(n=16)$ & $14-20$ & $-51 \pm 13$ & $0.9 \pm 0.7$ & $61 \pm 16$ \\
\hline$(n=4)$ & $>20$ & $-61 \pm 21$ & $0.5 \pm 0.4$ & $65 \pm 23$ \\
\hline \multicolumn{5}{|c|}{ E14 cortical neurons } \\
\hline$(n=8)$ & $14-20$ & $-63 \pm 6$ & $0.3 \pm 0.2$ & $76 \pm 24$ \\
\hline
\end{tabular}

Membrane properties of neurons derived from reprogrammed astroglial cells at discrete stages of maturation. Data from Pax6-, Mash1-, and Ngn2 transduced cells were grouped according to their age in culture, i.e., $7-13 \mathrm{~d}, 14-20 \mathrm{~d}$, and $>20 \mathrm{~d}$ and are shown separately for each TF as well as upon pooling the datasets within each age group (top 3 rows). For comparison, the same parameters were analysed in neurons derived from control transduced E14 cortical progenitors. Values are means \pm SD. The numbers of cells in each group tested is indicated in parentheses. Differences were analysed using Kruskal-Wallis test followed by a post hoc Dunn's test to compare between the different age groups as indicated by the connectors as well as between astroglia-derived and embryonic cortical neurons as indicated by the asterisks without connectors $\left({ }^{*} p<0.05 ;{ }^{* *} p<0.01 ;{ }^{* * *} p<0.001\right)$. All groups were tested against each other, but no significant differences were encountered between the different groups of astroglia-derived neurons (Pax6, Mash1, and Ngn2) at the same developmental stage.

neurons indeed received spontaneous synaptic input from cocultured cortical cells (Fig. 9a). These data demonstrate that astroglia-derived neurons can be recognized as functional targets of synapse formation competent neurons and are thus capable of assembling a functional postsynaptic compartment. However, the percentage of neurons derived from reprogrammed astroglia receiving spontaneous synaptic input was lower compared with neurons of embryonic origin in the same cultures and hence same age (Fig. 9b). To directly compare the degree of spontaneous synaptic input under the same conditions, we performed simultaneous pair recordings in voltage clamp from cocultured reprogrammed astroglial cells and cortical neurons. These recordings clearly illustrate the difference in synaptic input received by these cells. At an early stage in culture (8 DPI), neurons derived from reprogrammed astroglial cells were totally devoid of synaptic events, whereas cocultured cortical neurons already received substantial synaptic input (supplemental Fig. 5, available at www.jneurosci.org as supplemental material). At later stages of culturing, the reprogrammed cells did receive input but at lower frequencies compared with the cortical neurons (Fig. 9a). The data demonstrate that neurons derived from astroglia are indeed capable of receiving functional synaptic input but require longer than embryonic neurons to fully complete postsynaptic maturation. The fact that astroglia-derived neurons can establish a functional postsynaptic compartment indicates that the lack of synaptic activity in the absence of cocultured cells is most possibly attributable to an incomplete assembling of a functional presynapse within the period of culture.

\section{Discussion}

In the present study, we show that the proneural genes Ngn2 and Mash1 can induce a neuronal identity in cultures enriched for postnatal cortical astroglia as has been shown previously for Pax6 (Heins et al., 2002). By means of time-lapse microscopy, we provide direct evidence that it is indeed cells with astroglial characteristics that give rise to neuronal cells under these conditions.
Moreover, we demonstrate that the progeny derived from astroglial cells after forced expression of neurogenic fate determinants develop the functional properties of true neurons.

\section{Transition from an astroglial cell to a neuron}

Here we showed by several lines of evidence that astroglial cells from the postnatal cerebral cortex can be instructed to generate neurons. Not only the high proportion of astroglia in our cultures and the gradual appearance of cells with neuronal properties but also the live observation by time-lapse video microscopy showed that cells with astroglial properties of the cerebral cortex give rise to neurons after forced expression of Ngn2 but not after transduction with a control virus. Moreover, we can rule out an artifact by fusion of the VSV-G pseudotyped retroviruses with postmitotic neurons (Ackman et al., 2006), because this should then also occur after transduction with the control virus.

An important issue concerns the question whether the competence of nonneurogenic astroglia to respond to neurogenic fate determinants depends on the developmental stage. In the cerebral cortex, astroglia is generated from radial glia, i.e., a cell population that at earlier developmental stages generates neurons and neuronal precursors (Kriegstein and Götz, 2003). Thus, the competence of postnatal cortical astroglia to become reprogrammed by neurogenic fate determinants may be attributable to the retention of some neurogenic potential inherited from their radial glia ancestors, a potential that may then become lost during additional maturation. Astroglial maturation may be accompanied by epigenetic modifications that may make astroglial differentiation essentially irreversible. However, there is evidence suggesting that astroglial cells can dedifferentiate after brain injury (Ridet et al., 1997) or in cancer (Bachoo et al., 2002). In fact, whereas astroglial cells in cultures are quite distinct from mature quiescent astroglia normally found in the cortex, they resemble in many aspects reactive astroglia as found after brain injury (Ridet et al., 1997). Given the observation that retroviral targeting of Pax6 to proliferative cells within a cortical lesion induces the generation of doublecortin-positive progeny (Buffo et al., 2005), it is tempting to speculate that these neuroblast-like cells have indeed been generated by reactive astroglia.

\section{Physiological properties of astroglia-derived neurons}

The electrophysiological characterization of neurons derived from reprogrammed astroglia reveals that these cells do not only express proteins characteristic of immature neurons such as TuJ1 (Heins et al., 2002) but in fact differentiate into excitable cells. We show here that the neurons derived from reprogrammed astroglia gradually acquire the machinery required for generation of Hodgkin-Huxley-type action potentials, i.e., voltage-dependent $\mathrm{Na}^{+}$and $\mathrm{K}^{+}$channels. In contrast, control transduced astroglia were electrophysiologically passive as described for mature astroglia (Zhou et al., 2006). Like embryonic cortical neurons, progeny of reprogrammed astroglia was often found to be capable of sustaining repetitive discharge patterns. Furthermore, additional ac- 
tive conductances such as $\mathrm{Ca}^{2+}$-activated $\mathrm{K}^{+}$channels may account for the slow afterhyperpolarization in some of these neurons, allowing for adaptation and accommodation of spike discharge. Moreover, neurons derived from reprogrammed astroglia also express functional neurotransmitter receptors that enable them to receive synaptic input from cocultured neurons. These data suggest that these cells also possess the machinery required for establishing a functional postsynaptic compartment. Our findings show for the first time that postnatal astroglia of the cerebral cortex can be reprogrammed toward the generation of functional neurons.

Surprisingly, our data also show that expression of a single TF is sufficient to initiate a quite comprehensive program for neuronal differentiation in postnatal astroglia of the cerebral cortex. Some of the genes underlying the acquisition of membrane excitability and synapse formation may be direct targets of the neurogenic TFs studied here (Mattar et al., 2004). However, many of the genes required for neuronal differentiation are thought to be silenced by repressor complexes, such as the repressor element 1-silencing transcription factor (REST) (Ballas et al., 2005), a silencer gene that represses, for instance, the expression of type II sodium channels and neurotransmitter receptors in non-neuronal cells such as astrocytes (Chong et al., 1995; Schoenherr et al., 1996). Thus, despite the expression of REST in astroglia (Nakatani et al., 2005), expression of a single neurogenic TF is apparently sufficient to achieve a considerable reprogramming in cellular identity, from an astroglia to a neuron, including the expression of voltage-dependent channels and neurotransmitter receptors.

However, despite the acquisition of many functional neuronal characteristics, neurons derived from reprogrammed astroglia failed to generate a functional presynaptic output within the time window of culturing, as evidenced by the absence of spontaneous or evoked release. Such failure may be attributable to a delay in the maturation process. In support of a delayed maturation, we found the following. First, AP amplitudes of reprogrammed cells increased over time but generally took longer to reach the levels of neurons derived from embryonic precursors. Second, input resistance, a function of cell morphology and channel density, gradually decreased, indicating progressive cell growth and increased channel incorporation, yet at a slower pace in reprogrammed neurons compared with those originating from embryonic neuronal precursors. Third, astroglia-derived neurons received less synaptic input compared with embryonic neurons, suggesting that the processes underlying synapse formation between cortical neurons and neurons derived from astroglia may be at a competitive disadvantage compared with those between cortical neurons alone. Intriguingly, the pace at which adult-born neurons mature in the dentate gyrus of the hippocampus is also delayed compared with early-born neurons (Overstreet-Wadiche et al., 2006a). Because these cells are generated from precursors with astroglial identity (Seri et al., 2001, 2004), such differences in maturation might be attributable to cell-autonomous disparities between adult versus early progenitors of dentate granule cells. Because seizure activity can markedly speed up differentiation of adult-born granule cells (Overstreet-Wadiche et al., 2006b), environmental factors may be crucial in determining the pace of maturation. In any case, whether and when adult-born neurons start to generate functional presynaptic output has not yet been determined.

The finding that reprogrammed astroglia were recognized as postsynaptic targets and were successfully innervated by cocultured embryonic neurons, but themselves failed to provide presynaptic output within the period of culturing, may suggest that the competences to establish functional presynaptic and a postsynaptic compartments are regulated by distinct molecular programs. However, at the present state, we cannot exclude the possibility that, with additional maturation, astroglia-derived neurons eventually generate a functional presynaptic output. A direct test of this possibility was hampered by the fact that we could not maintain these cultures at the same high quality beyond a 4 week period. 

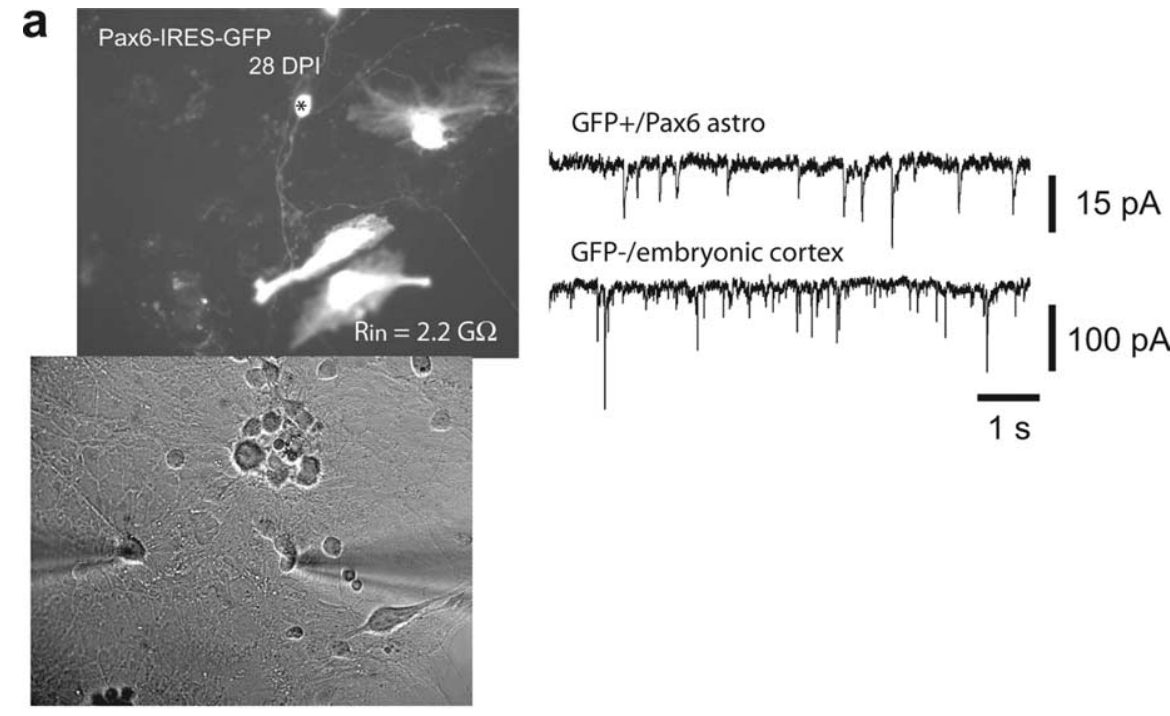

b

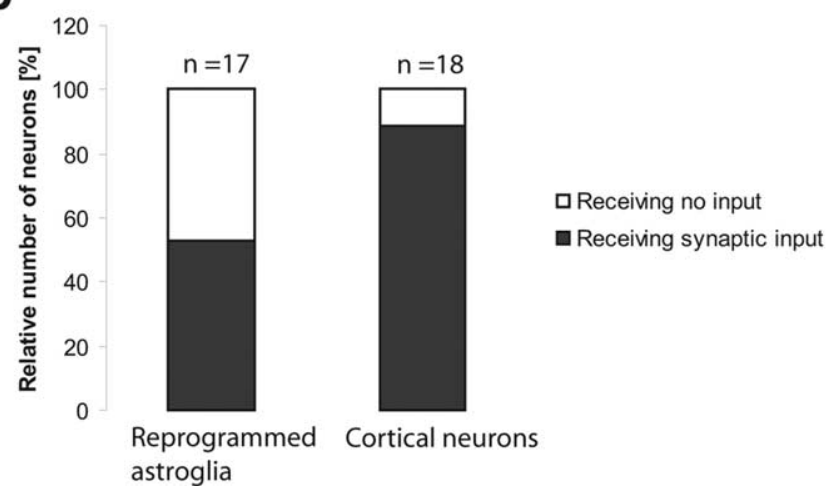

Figure 9. Reprogrammed astroglial cells receive functional synaptic input. $\boldsymbol{a}$, Example of a dual recording of a neuron derived from a Pax6 reprogrammed cell and a cocultured neuron from E16 cerebral cortex. Both neurons receive synaptic input, but the frequency and amplitude of synaptic events in the glia-derived cell are notably lower compared with the E16 cortical neuron. $\boldsymbol{b}$, Percentage of neurons derived from reprogrammed astroglial precursors and cocultured cortical neurons receiving synaptic input in coculture.

Although lack of a functional presynaptic output prevented us to assess by electrophysiological means whether reprogramming by the different neurogenic fate determinants resulted in the generation of distinct neuronal phenotypes, immunocytochemical analysis revealed that Ngn2, but not Mash1, transduced cells upregulated the T-box transcription factor Tbr1. Tbr1 is known to be selectively, albeit transiently, expressed in virtually all neurons acquiring a glutamatergic identity in the developing telencephalon and to be retained only in specific subpopulations of glutamatergic neurons in the adult (Hevner et al., 2006). The fact that Tbr1 expression was found only in approximately one-third of Ngn2-transduced cells may be explained by the following three scenarios: (1) the remaining two-thirds had acquire a distinct neuronal subtype identity, consistent with the fact that Ngn2 is involved in the specification of other neuron populations than glutamatergic ones (Mizuguchi et al., 2001; Kele et al., 2006), (2) they remain immature or (3) Tbr1 expression may be transient and therefore found only in a subpopulation at a given time point. Interestingly, we have found previously that Tbr1 is expressed in a similar percentage of neurons derived from in vitro expanded adult neural stem cells (Berninger et al., 2007). However, all neurons derived from Ngn2-transduced adult neural stem cells reaching maturity were found to establish exclusively glutamatergic synapses. To determine whether Ngn2-transduced astroglia indeed acquire a glutamatergic identity, it will be necessary to establish conditions that successfully induce synaptogenesis to test unambiguously for the transmitter used. However, the data presented here at least suggest that Ngn2 and Mash1 reprogrammed astroglial cells may adopt distinct neuronal identities.

\section{Conclusions}

Despite several reports on redirecting glial cells or their precursors toward a neuronal fate (Laywell et al., 2000; Magavi et al., 2000; Heins et al., 2002; Buffo et al., 2005), none of these studies examined the functional properties of the cells expressing TuJ1 or other neuronal markers. Thus, our present data provide the first evidence that neurons derived from reprogrammed glia do indeed acquire the physiological hallmarks of functional neurons, a necessary prerequisite for functional repair.

\section{References}

Ackman JB, Siddiqi F, Walikonis RS, LoTurco JJ (2006) Fusion of microglia with pyramidal neurons after retroviral infection. J Neurosci 26:11413-11422.

Anderson S, Mione M, Yun K, Rubenstein JLR (1999) Differential origins of neocortical projection and local circuit neurons: role of Dlx genes in neocortical interneuronogenesis. Cereb Cortex 9:646-654

Bachoo RM, Maher EA, Ligon KL, Sharpless NE, Chan SS, You MJ, Tang Y, DeFrances J, Stover E, Weissleder R, Rowitch DH, Louis DN, DePinho RA (2002) Convergent mechanisms governing terminal differentiation and transformation along the neural stem cell to astrocyte axis. Cancer Cell 1:269-277.

Ballas N, Grunseich C, Lu DD, Speh JC, Mandel G (2005) REST and its corepressors mediate plasticity of neuronal gene chromatin throughout neurogenesis. Cell 121:645-657.

Berninger B, Guillemot F, Götz M (2007) Directing neurotransmitter identity of neurons derived from expanded adult neural stem cells. Eur J Neurosci 25:2581-2590.

Buffo A, Vosko MR, Ertürk D, Hamann GF, Jucker M, Rowitch D, Götz M (2005) Expression pattern of the transcription factor Olig2 in response to brain injuries: implications for neuronal repair. Proc Natl Acad Sci USA 102:18183-18188.

Chong JA, Tapia-Ramirez J, Kim S, Toledo-Aral JJ, Zheng Y, Boutros MC, Altshuller YM, Frohman MA, Kraner SD, Mandel G (1995) REST: a mammalian silencer protein that restricts sodium channel gene expression to neurons. Cell 80:949-957.

Doetsch F, Caille I, Lim DA, Garcia-Verdugo JM, Alvarez-Buylla A (1999) Subventricular zone astrocytes are neural stem cells in the adult mammalian brain. Cell 97:703-716.

Fitzsimonds RM, Song HJ, Poo MM (1997) Propagation of activitydependent synaptic depression in simple neural networks. Nature 388:439-448

Garcia AD, Doan NB, Imura T, Bush TG, Sofroniew MV (2004) GFAPexpressing progenitors are the principal source of constitutive neurogenesis in adult mouse forebrain. Nat Neurosci 7:1233-1241.

Götz M, Stoykova A, Gruss P (1998) Pax6 controls radial glia differentiation in the cerebral cortex. Neuron 21:1031-1044.

Guillemot F (2005) Cellular and molecular control of neurogenesis in the mammalian telencephalon. Curr Opin Cell Biol 17:639-647. 
Hack MA, Sugimori M, Lundberg C, Nakafuku M, Götz M (2004) Regionalization and fate specification in neurospheres: the role of Olig2 and Pax6. Mol Cell Neurosci 25:664-678.

Hack MA, Saghatelyan A, de Chevigny A, Ashery-Padan R, Lledo PM, Götz M (2005) Neuronal fate determinants of adult olfactory bulb neurogenesis. Nat Neurosci 8:865-872.

Hartfuss E, Galli R, Heins N, Götz M (2001) Characterization of CNS precursor subtypes and radial glia. Dev Biol 229:15-30.

Hatakeyama J, Tomita K, Inoue T, Kageyama R (2001) Roles of homeobox and bHLH genes in specification of a retinal cell type. Development 128:1313-1322.

Heins N, Malatesta P, Cecconi F, Nakafuku M, Tucker KL, Hack MA, Chapouton P, Barde YA, Götz M (2002) Glial cells generate neurons: the role of the transcription factor Pax6. Nat Neurosci 5:308-315.

Hevner RF, HodgeRD, Daza RA, Englund C (2006) Transcription factors in glutamatergic neurogenesis: conserved programs in neocrotex, cerebellum, and adult hippocampus. Neurosci Res 55:223-233.

Horn R, Marty A (1988) Muscarinic activation of ionic currents measured by a new whole-cell recording method. J Gen Physiol 92:145-159.

Kele J, Simplicio N, Ferri ALM, Mira H, Guillemot F, Arenas E, Ang S-L (2006) Neurogenin 2 is required for the development of ventral midbrain dopaminergic neurons. Development 133:495-505.

Kondo T, Raff M (2000) Oligodendrocyte precursor cells reprogrammed to become multipotential CNS stem cells. Science 289:1754-1757.

Kriegstein AR, Götz M (2003) Radial glia:a matter of cell fate. Glia 43:37-43.

Laywell ED, Rakic P, Kukekov VG, Holland EC, Steindler DA (2000) Identification of a multipotent astrocytic stem cell in the immature and adult mouse brain. Proc Natl Acad Sci USA 97:13883-13888.

Magavi SS, Leavitt BR, Macklis JD (2000) Induction of neurogenesis in the neocortex of adult mice. Nature 405:951-955.

Malatesta P, Hartfuss E, Götz M (2000) Isolation of radial glial cells by fluorescent-activated cell sorting reveals a neuronal lineage. Development 127:5253-5263.

Mattar P, Britz O, Johannes C, Nieto M, Ma L, Rebeyka A, Klenin N, Polleux F, Guillemot F, Schuurmans C (2004) A screen for downstream effectors of Neurogenin2 in the embryonic neocortex. Dev Biol 273:373-389.

Merkle FT, Tramontin AD, García-Verdugo J, Alvarez-Buylla A (2004) Radial glia give rise to adult neural stem cells in the subventricular zone. Proc Natl Acad Sci USA 101:17528-17532.

Miyata T, Kawaguchi A, Okano H, Ogawa M (2001) Asymmetric inheritance of radial glial fibers by cortical neurons. Neuron 31:727-741.

Mizuguchi R, Sugimori M, Takebayashi H, Kosako H, Nagao M, Yoshida S, Nabeshima Y, Shimamura K, Nakafuku M (2001) Combinatorial roles of olig2 and neurogenin 2 in the coordinated induction of pan-neuronal and subtype-specific properties of motoneurons. Neuron 31:757-771.

Morrow T, Song MR, Gosh A (2001) Sequential specification of neurons and glia by developmentally regulated extracellular factors. Development 128:3585-3594.

Nakatani T, Ueno S, Mori N, Matsuoka I (2005) Role of NRSF/REST in the molecular mechanisms regulating neural-specific expression of trkC/ neurotrophin-3 receptor gene. Brain Res Mol Brain Res 135:249-259.

Noctor SC, Flint AC, Weissman TA, Dammerman RS, Kriegstein AR (2001) Neurons derived from radial glial cells establish radial units in neocortex. Nature 409:714-720.

Nolte C, Matyash M, Pivneva T, Schipke CG, Ohlemeyer C, Hanisch UK, Kirchhoff F, Kettenmann H (2001) GFAP promoter-controlled EGFexpressing transgenic mice: a tool to visualize astrocytes and astrogliosisin living brain tissue. Glia 33:72-86.

Overstreet-Wadiche LS, Bensen AL, Westbrook GL (2006a) Delayed development of adult-generated granule cells in dentate gyrus. J Neurosci 26:2326-2334.

Overstreet-Wadiche LS, Bromberg DA, Bensen AL, Westbrook GL (2006b) Seizures accelerate functional integration of adult-generated granule cells. J Neurosci 26:4095-4103.

Poitras L, Ghanem N, Hatch G, Ekker M (2007) The proneural determinant MASH1 regulates forebrain Dlx1/2 expression through the I12b intergenic enhancer. Development 134:1755-1765.

Rae J, Cooper K, Gates P, Watsky M (1991) Low access resistance perforated patch recordings using amphotericin B. J Neurosci Methods 37:15-26.

Ridet JL, Malhotra SK, Privat A, Gage FH (1997) Reactive astrocytes: cellular and molecular cues to biological function. Trends Neurosci 20:570-577.

Schoenherr CJ, Paquette AJ, Anderson DJ (1996) Identification of potential target genes for the neuron-restrictive silencer factor. Proc Natl Acad Sci USA 93:9881-9886.

Seri B, Garcia-Verdugo JM, McEwen BS, Alvarez-Buylla A (2001) Astrocytes give rise to new neurons in the adult mammalian hippocampus. J Neurosci 21:7153-7160.

Seri B, Garcia-Verdugo JM, Collado-Morente L, McEwen BS, Alvarez-Buylla A (2004) Cell types, lineage, and architecture of the germinal zone in the adult dentate gyrus. J Comp Neurol 478:359-378.

Song HJ, Stevens CF, Gage FH (2002) Neural stem cells from adult hippocampus develop essential properties of functional CNS neurons. Nat Neurosci 5:438-445.

Tamamaki N, Nakamura K, Okamoto K, Kaneko T (2001) Radial glia is a progenitor of neocortical neurons in the developing cerebral cortex. Neurosci Res 41:51-60.

Ventura RE, Goldman JE (2007) Dorsal radial glia generate olfactory bulb interneurons in the postnatal murine brain. J Neurosci 27:4297-4302.

Warren N, Caric D, Pratt T, Clausen JA, Asavaritikrai P, Mason JO, Hill RE, Price DJ (1999) The transcription factor, Pax6, is required for cell proliferation and differentiation in the developing cerebral cortex. Cereb Cortex 9:627-635.

Zheng W, Nowakowski RS, Vaccarino FM (2004) Fibroblast growth factor 2 is required for maintaining the neural stem cell pool in the mouse brain subventricular zone. Dev Neurosci 26:181-196.

Zhou M, Schools GP, Kimelberg HK (2006) Development of GLAST(+) astrocytes and $\mathrm{NG2}(+)$ glia in rat hippocampus CA1: mature astrocytes are electrophysiologically passive. J Neurophysiol 95:134-143. 